ORIGINAL ARTICLE

\title{
Gene-gene interaction in folate-related genes and risk of neural tube defects in a UK population
}

\author{
C L Relton, C S Wilding, M S Pearce, A J Laffling, P A Jonas, S A Lynch, E J Tawn, J Burn
}

J Med Genet 2004;41:256-260. doi: 10.1136/jmg.2003.010694

See end of article for authors' affiliations

a thors' affilicions

Correspondence to: $\operatorname{Dr} C$ L Relton, Paediatric and Lifecourse

Epidemiology Research

Group, School of Clinical

Medical Sciences,

Newcastle University, Sir

James Spence Institute,

Royal Victoria Infirmary,

Newcastle upon Tyne,

NE14LP, UK; c.l.relton@

ncl.ac.uk

Revised version received 19 December 2003

Accepted for publication

8 January 2004

\begin{abstract}
Objective: To investigate the contribution of polymorphic variation in genes involved in the folatedependent homocysteine pathway in the aetiology of neural tube defects (NTD).

Design: Case-control association study.

Subjects: A total of 530 individuals from families affected by NTD, 645 maternal controls, and 602 healthy newborn controls from the northern UK.

Main outcome measures: Seven polymorphisms in six genes coding for proteins in the folate-dependent homocysteine pathway (MTHFR 677C $\rightarrow$ T, MTHFR 1298A $\rightarrow$ C, MTRR 66A $\rightarrow$ G, SHMT 1420C $\rightarrow$ T, CBS 844ins68, GCPII $1561 \mathrm{C} \rightarrow \mathrm{T}, R F C-180 \mathrm{G} \rightarrow \mathrm{A})$. The impact of each polymorphism and the effect of genegene interactions (epistasis) upon risk of NTD were assessed using logistic regression analysis.

Results: The MTHFR $677 \mathrm{C} \rightarrow$ T polymorphism was shown to represent a risk factor in NTD cases (CC v $\mathrm{CT}+\Pi$ odds ratio (OR) $2.03[95 \%$ confidence interval $(\mathrm{Cl}) 1.09,3.79] \mathrm{p}=0.025)$ and the MTRR $66 \mathrm{~A} \rightarrow \mathrm{G}$ polymorphism was shown to exert a protective effect in NTD cases (AA v AG+GG OR 0.31 [95\% Cl 0.10, 0.94] $p=0.04$ ). When statistical tests for interaction were conducted, three genotype combinations in cases (MTRR/GCPII; MTHFR 677/C $\beta$ S; MTHFR 677/MTRR) and one combination in case mothers (C $\beta S$ / RFC-1) were shown to elevate NTD risk. Maternal-fetal interaction was also detected when offspring carried the MTHFR $677 \mathrm{C} \rightarrow T$ variant and mothers carried the MTRR $66 \mathrm{~A} \rightarrow \mathrm{G}$ variant, resulting in a significantly elevated risk of NTD.

Conclusion: Both independent genetic effects and gene-gene interaction were observed in relation to NTD risk. Multi-locus rather than single locus analysis might be preferable to gain an accurate assessment of genetic susceptibility to NTD.
\end{abstract}

$\mathrm{F}$ ailure of closure of the developing neural tube leads to a number of related conditions collectively termed neural tube defects (NTD). The precise aetiology of such conditions is not known, but can involve a number of environmental and genetic factors. ${ }^{12}$ NTD is known to have a significant genetic component, with multiple cases known to occur within one pedigree and women affected by a NTD pregnancy having an elevated risk of subsequent NTD pregnancies. A common genetic basis is assumed but since various forms or degrees of severity of NTD have been observed in a single family, susceptibility is probably dictated by a polygenic mode of inheritance as well as being modulated by environmental exposures.

Significantly, mothers of NTD affected offspring typically display lower than normal plasma folate levels ${ }^{34}$ and an elevation in homocysteine (Hcy) levels, ${ }^{5}$ indicating that defects in the folate-dependent Hcy pathway may play an important role in the aetiology of these conditions. It is also now well accepted that periconceptional supplementation with folic acid substantially decreases the risk of occurrence and recurrence (by up to 70\%) of neural tube defects (reviewed by Lucock ${ }^{2}$ ). These observations have resulted in considerable interest in the study of genetic polymorphisms in loci of the folate-dependent Hcy metabolic pathway as risk factors for NTD, as a functional defect at any such locus could impact upon the distribution of folate, Hcy, and their intermediates.

Many enzyme-coding loci of the folate-dependent Hcy pathway have now been screened for mutations. The first such polymorphism identified as a risk factor for NTD was the $\mathrm{C} \rightarrow \mathrm{T}$ mutation at position 677 of the MTHFR gene. ${ }^{46}$ Additional polymorphisms in alternative loci involved in folate metabolism, and folate transport, have since been examined as potential risk factors. ${ }^{1278}$ Although individual polymorphisms have been implicated as NTD risk factors for certain populations, as yet no single polymorphism in any candidate gene has been implicated as a risk factor in all studies. Digenic inheritance, in which mutations in each of two unlinked genes results in the disease phenotype, has been implicated in numerous diseases, including the NTD related holoprosencephaly. ${ }^{9}$ Given the interconnected nature of the folate-dependent Hcy pathway it is possible that particular combinations of genetic variants may underlie NTD susceptibility. However, to date no studied locus combination has proved to be the single, or a major, causal agent of NTD in any populations studied. This is, to some extent, explainable by the finding that polymorphisms vary greatly in allele frequency between ethnic groups and populations. ${ }^{1011}$ The creation of a human genome single nucleotide polymorphism (SNP) map has highlighted the frequency with which SNPs occur across the genome. With an SNP being present every 1000 bases (on average) it is probable that no two individuals will possess the same allelic combination. By virtue of this, it is likely that critical combinations of variant alleles will be responsible for increasing disease susceptibility. In the case of NTD it is hypothesised that a mutation load in folate-related Hcy metabolism genes which, in some instances, cannot be overcome by exogenous nutrient supplementation, might be sufficient to cause NTD. Since few studies examine multiple polymorphisms, it may also be that the crucial gene-gene

Abbreviations: Hcy, homocysteine; NTD, neural tube defects; SNP, single nucleotide polymorphism; TDT, transmission disequilibrium testing 
interaction is, as yet, unexamined. As such, it is important to not only measure allele frequencies of candidate gene polymorphisms in new NTD cohorts, but to examine the impact of new combinations of loci in each population studied. Here we examine a suite of seven polymorphisms in six folate pathway genes for their impact on NTD risk in a collection of NTD patients and families, with controls, from the northern UK, where NTD prevalence is relatively high at a rate of 17.9 per 10000 births. $^{12}$

\section{METHODS \\ Subjects}

The study population consisted of individuals with NTDs $(n=219)$, mothers of NTD cases $(n=211)$, and where both case and mother were present, fathers were invited to participate $(n=100)$ in order to compile case-parent triads. Of the total study group, 126 case mother-child pairs and 275 control mother-child pairs were available for analysis, and in all other instances only the mother or child were enrolled onto the study. Recruitment took place throughout the northern region of the UK between 1993 and 2002 through the Northern Genetics Service. Participants were visited by a genetic research nurse who gained informed consent prior to obtaining a family history, completing a questionnaire with the mother of the affected individual, and taking a venous blood sample, or buccal swab sample, from family members for DNA extraction. Public awareness of the research study was raised with local media assistance and liaison with the Association for Spina Bifida and Hydrocephalus (ASBAH). Information about the type of defect was available for 203 of the NTD cases: 109 (53.7\%) spina bifida, 51 (25.1\%) spina bifida occulta, 32 (15.8\%) anencephaly, and 11 (5.4\%) other NTD. In addition, information was available in 200 of 223 cases pertaining to the affected status of offspring born to case mothers (multiple affected pregnancies were included): $126(63.0 \%)$ spina bifida, $39(19.5 \%)$ spina bifida occulta, 31 (15.5\%) anencephaly, and four $(2.0 \%)$ other NTD. Only those cases with an unequivocal spina bifida occulta diagnosis, displaying clear signs such as haemangioma, significant dimple, hairy patch, or associated neurological impairment were included in the study cohort. $X$ ray evidence was obtained in some instances. The control population was drawn from the North Cumbria Community Genetics Project (NCCGP). ${ }^{13}$ The NCCGP is a DNA and tissue bank consisting of samples collected consecutively between 1996 and 2003. Cord blood was collected from newborns from 1996 and from 1999, mothers were asked for their consent to retain antenatal blood samples. Over 7000 infant samples and 3000 maternal samples have been collected representing over $85 \%$ of births at West Cumberland Hospital, Whitehaven, Cumbria, UK. The control group were Caucasian women of childbearing age and did not differ ethnically/racially from the control group. Venous blood samples (mother; $n=645$ ) or cord blood samples (child; $n=602$ ) were provided for DNA extraction. Excluded from the control population were pregnancies in which the mother declared a family history of NTD or gave birth to a child with NTD. Ethical approval for this study was obtained from the Northern and Yorkshire MREC and West Cumbria LREC.

\section{Genetic analyses}

DNA was extracted from either blood samples or mouthswabs using standard techniques. Seven polymorphisms in six folate pathway genes were examined by PCR-RFLP. Table 1 lists the polymorphisms examined and reaction conditions employed for amplification. ${ }^{14-21}$ Not all loci were amplified from every subject due to problems with DNA quality, quantity, and PCR amplification.

\section{Statistical analyses}

Hardy-Weinberg tests on genotypic data were conducted using the method of Guo and Thompson. ${ }^{22}$ The method of Schaid and Jacobsen ${ }^{23}$ was applied where appropriate to correct for deviation from Hardy-Weinberg equilibrium (HWE) (that is if HWE was not observed). Logistic regression modeling of all seven loci was undertaken to investigate both individual locus effects and gene-gene interaction in cases and case mothers. In addition, multivariate logistic regression analysis of joint mother-child genotypes was applied to determine whether maternal-fetal interaction was significantly influencing disease risk. For each locus the wild-type genotype was compared to pooled heterozygote and homozygote variants. Results were represented as odds ratios with 95\% confidence intervals (CI). Statistical analysis was undertaken using the STATA software package. Transmission disequilibrium testing (TDT) was undertaken using the method of van den Oord et $a^{24}$ and incorporated data from both complete and incomplete trios $(n=124)$.

\section{RESULTS}

The number of individuals and genotype frequency for each of the seven studied polymorphisms are presented in Table 2. Genotypes at MTRR were not in Hardy-Weinberg equilibrium (HWE) for NTD cases, case fathers, or control infants (table 2) but all other comparisons were within HWE.

A case-control comparison of individual loci was conducted for NTD cases using a multivariate logistic regression model (table 3). After adjusting for all other genotypes, significant effects were observed which were independent of other genotypes. The MTHFR $677 \mathrm{C} \rightarrow \mathrm{T}$ polymorphism was shown to represent a significant risk factor in NTD cases (CC $v$ CT+TT OR 2.03 [95\% CI 1.09, 3.79]) and MTRR 66A $\rightarrow$ G conferred a protective effect in the same group (AA $v$ AG+GG OR 0.31 [95\% CI 0.10, 0.94]. When mothers of NTD offspring were considered as the "case" phenotype a case-control analysis of individual locus genotypes produced no significant results (table 3).

Logistic regression analysis of all seven loci for evidence of interaction showed three genotype combinations to confer a risk of NTD in cases: GCPII 1561C $\rightarrow \mathrm{T} \times M T R R \quad 66 \mathrm{~A} \rightarrow \mathrm{G}$ $(\mathrm{p}=0.004) ; \quad$ MTHFR $\quad 677 \mathrm{C} \rightarrow \mathrm{T} \times M T R R \quad 66 \mathrm{~A} \rightarrow \mathrm{G} \quad(\mathrm{p}=0.003) ;$ and MTHFR $677 \mathrm{C} \rightarrow \mathrm{T} \times C \beta S$ 844ins68 $(\mathrm{p}=0.007)$. One combination of genotypes was shown to represent a significant risk factor for NTD pregnancy: $R F C-1 \quad 80 \mathrm{G} \rightarrow \mathrm{A} \times C \beta S$ 844ins68 $(\mathrm{p}=0.014)$.

Analysis of all combinations of mother-child genotypes for maternal-fetal interaction produced only one statistically significant result: maternal MTRR $66 \mathrm{~A} \rightarrow \mathrm{G} \times$ fetal $M T H F R$ $677 \mathrm{C} \rightarrow \mathrm{T}(\mathrm{p}=0.001)$.

Transmission disequilibrium testing (TDT) was undertaken using both complete and incomplete trios $(n=124)^{24}$ to ascertain whether any alleles were preferentially transmitted from parents to affected offspring. No significant observations were detected.

\section{DISCUSSION}

NTD is recognised to have a complex aetiology, involving both environmental and genetic factors. Although enzymes involved in the folate-dependent Hcy pathway are strongly implicated in NTD, the numerous candidates and wide ethnic and population level differences in allele frequencies of their polymorphic variants ${ }^{10}{ }^{11}$ suggest that no single genetic factor is likely to be responsible for NTD. Estimation of allele frequencies in new sample sets and examination of potential gene-gene interactions must therefore be undertaken in several independent populations. Here we have undertaken a large-scale analysis of seven single nucleotide polymorphisms in six candidate genes involved in the folate-dependent Hcy 
Table 1 PCR-RFLP parameters for analysis of seven candidate loci

\begin{tabular}{|c|c|c|c|c|c|c|}
\hline Locus* & Sense primer & Antisense primer & PCR conditions & Buffert & $\begin{array}{l}\text { Restriction } \\
\text { endonuclease }\end{array}$ & Gel/ABI \\
\hline MTHFR $677 \mathrm{C} \rightarrow \mathrm{T}$ & $\begin{array}{l}\text { 5'-TGA AGG AGA AGG TGT } \\
\text { CTG CGG GA-3' }\end{array}$ & $\begin{array}{l}\text { 5'-TGA GAG TGG GGT } \\
\text { GGA GGG AGC } \Pi-3^{\prime}\end{array}$ & $\begin{array}{l}33 \times\left(96^{\circ} \mathrm{C} 30 \mathrm{~s},\right. \\
\left.61^{\circ} \mathrm{C} 30 \mathrm{~s}, 72^{\circ} \mathrm{C} 30 \mathrm{~s}\right)\end{array}$ & V & Hinf I & $A B I$ \\
\hline MTHFR $1298 \mathrm{~A} \rightarrow \mathrm{C}$ & $\begin{array}{l}\text { 5'-CTT TGG GGA GCT GAA } \\
\text { GGA CTA CTA C-3' }\end{array}$ & $\begin{array}{l}\text { 5'-CAG GGG ATG AAC } \\
\text { CAG GGT CC-3' }\end{array}$ & $\begin{array}{l}38 \times\left(95^{\circ} \mathrm{C} 30 \mathrm{~s},\right. \\
\left.59^{\circ} \mathrm{C} 30 \mathrm{~s}, 72^{\circ} \mathrm{C} 30 \mathrm{~s}\right)\end{array}$ & V & Mbo II & $A B I$ \\
\hline MTRR $66 \mathrm{~A} \rightarrow \mathrm{G}$ & $\begin{array}{l}\text { 5'-GCA AAG GCC ATC GCA } \\
\text { GAA GAC AT-3' }\end{array}$ & $\begin{array}{l}\text { 5'-CAC Tत CCA ACC } \\
\text { AAA АTT CTT CAA AG-3' }\end{array}$ & $\begin{array}{l}30 \times\left(94^{\circ} \mathrm{C} 30 \mathrm{~s},\right. \\
\left.55^{\circ} \mathrm{C} 30 \mathrm{~s}, 72^{\circ} \mathrm{C} 30 \mathrm{~s}\right)\end{array}$ & V & Nde I & $A B I$ \\
\hline GCPII C1561T & $\begin{array}{l}\text { 5'-CAT TCT GGT AGG AAT } \\
\text { TIA GCA-3' }\end{array}$ & $\begin{array}{l}\text { 5'-AAA CAC CAC CTA } \\
\text { TGT TTA ACA-3' }\end{array}$ & $\begin{array}{l}35 \times\left(95^{\circ} \mathrm{C} 30 \mathrm{~s},\right. \\
\left.48^{\circ} \mathrm{C} 30 \mathrm{~s}, 72^{\circ} \mathrm{C} 30 \mathrm{~s}\right)\end{array}$ & 1 & Acc II & Gel \\
\hline C $\beta S$ 844ins68 & $\begin{array}{l}\text { 5'-GCA GTT GT AAC GGC } \\
\text { GGT AT-3' }\end{array}$ & $\begin{array}{l}\text { 5'-GT GTC TGC TCC } \\
\text { GTC TGG TT-3' }\end{array}$ & $\begin{array}{l}35 \times\left(94^{\circ} \mathrm{C} 30 \mathrm{~s},\right. \\
\left.57^{\circ} \mathrm{C} 30 \mathrm{~s}, 72^{\circ} \mathrm{C} 30 \mathrm{~s}\right)\end{array}$ & 1 & - & Gel \\
\hline$R F C-180 \mathrm{G} \rightarrow \mathrm{A}$ & $\begin{array}{l}\text { 5'-AGT GTC ACC TTC GTC } \\
\text { CCC TC-3' }\end{array}$ & $\begin{array}{l}\text { 5'-CTC CCG CGT GAA } \\
\text { GTT CTT-3' }\end{array}$ & $\begin{array}{l}35 \times\left(94^{\circ} \mathrm{C} 30 \mathrm{~s},\right. \\
\left.56^{\circ} \mathrm{C} 30 \mathrm{~s}, 72^{\circ} \mathrm{C} 45 \mathrm{~s}\right)\end{array}$ & V & Hha I & $A B I$ \\
\hline$S H M T 1420 C \rightarrow T$ & $\begin{array}{l}\text { 5'-AGA GIT CAA GGA GAG } \\
\text { ACT GGC AG-3' }\end{array}$ & $\begin{array}{l}5^{\prime}-T T T \text { GCC CTA CAC } \\
\text { CAC CAT CT-3' }\end{array}$ & $\begin{array}{l}35 \times\left(94^{\circ} \mathrm{C} 30 \mathrm{~s},\right. \\
\left.56^{\circ} \mathrm{C} 30 \mathrm{~s}, 72^{\circ} \mathrm{C} 30 \mathrm{~s}\right)\end{array}$ & V & Ear I & Gel \\
\hline
\end{tabular}

pathway and undertaken logistic regression and TDT analysis of results. The current study investigates the potential role of MTHFR $677 \mathrm{C} \rightarrow \mathrm{T}$, MTHFR $1298 \mathrm{~A} \rightarrow \mathrm{C}, \quad$ MTRR $\quad 66 \mathrm{~A} \rightarrow \mathrm{G}$, $C B S$ 844ins68, GCPII $1561 \mathrm{C} \rightarrow \mathrm{T}, \quad R F C-1 \quad 80 \mathrm{G} \rightarrow \mathrm{A}$, and $S H M T$ 1420C $\rightarrow$ T in NTD susceptibility in a Caucasian UK population.
A clear association between MTHFR $677 \mathrm{C} \rightarrow$ T genotype and NTD risk was observed in the NTD case population investigated in this study (CC $v$ CT+TT OR 2.03 [95\% CI $1.09,3.79])$. A number of previous studies have established the common $677 \mathrm{C} \rightarrow \mathrm{T}$ variant of MTHFR as an independent risk factor associated with NTD. ${ }^{4}$ Although several

Table 2 Genotype frequencies, allele frequencies, and tests for conformation to HardyWeinberg equilibrium at seven candidate loci

\begin{tabular}{|c|c|c|c|c|c|c|}
\hline \multirow[b]{2}{*}{ MTHFR $677 \mathrm{C} \rightarrow \mathrm{T}$} & \multicolumn{2}{|c|}{ Genotype $\boldsymbol{n}(\%)$} & \multicolumn{3}{|c|}{ Allele frequency } & \multirow[t]{2}{*}{$H-W p$} \\
\hline & $\mathrm{C} / \mathrm{C}$ & $\mathrm{C} / \mathrm{T}$ & $\mathrm{T} / \mathrm{T}$ & $\mathrm{C}$ & $\mathrm{T}$ & \\
\hline NTD case & $92(46.0)$ & $78(39.0)$ & $30(15.0)$ & 0.655 & 0.345 & 0.060 \\
\hline NTD case father & $34(38.6)$ & $37(42.0)$ & 17 (19.3) & 0.597 & 0.403 & 0.268 \\
\hline NTD case mother & $86(46.2)$ & $78(41.9)$ & $22(11.8)$ & 0.672 & 0.328 & 0.509 \\
\hline Control child & $267(46.2)$ & $247(42.7)$ & $64(11.1)$ & 0.676 & 0.324 & 0.569 \\
\hline Control mother & $191(37.3)$ & $254(49.6)$ & $67(13.1)$ & 0.621 & 0.379 & 0.260 \\
\hline MTHFR $1298 \mathrm{~A} \rightarrow \mathrm{C}$ & $\mathrm{A} / \mathrm{A}$ & $\mathrm{A} / \mathrm{C}$ & $\mathrm{C} / \mathrm{C}$ & A & C & \\
\hline NTD case & 91 (46.9) & $80(41.2)$ & $23(11.9)$ & 0.675 & 0.325 & 0.415 \\
\hline NTD case father & $35(45.5)$ & $34(44.2)$ & $8(10.4)$ & 0.675 & 0.325 & 1.000 \\
\hline NTD case mother & $80(43.2)$ & $83(44.9)$ & $22(11.9)$ & 0.657 & 0.343 & 1.000 \\
\hline Control child & $279(47.8)$ & $235(40.2)$ & $70(12.0)$ & 0.679 & 0.321 & 0.071 \\
\hline Control mother & $222(42.5)$ & $236(45.2)$ & 64 (12.3) & 0.651 & 0.349 & 0.923 \\
\hline MTRR $66 \mathrm{~A} \rightarrow \mathrm{G}$ & $\mathrm{A} / \mathrm{A}$ & $\mathrm{A} / \mathrm{G}$ & $G / G$ & A & G & \\
\hline NTD case & $23(11.4)$ & $125(62.2)$ & $53(26.4)$ & 0.425 & 0.575 & 0.000 \\
\hline NTD case father & $7(8.0)$ & $50(56.8)$ & $31(35.2)$ & 0.364 & 0.636 & 0.048 \\
\hline NTD case mother & $28(13.8)$ & $107(52.7)$ & $68(33.5)$ & 0.401 & 0.599 & 0.191 \\
\hline Control child & $28(4.7)$ & $265(44.1)$ & $308(51.2)$ & 0.267 & 0.733 & 0.002 \\
\hline Control mother & $58(10.9)$ & $263(49.4)$ & $211(39.7)$ & 0.356 & 0.644 & 0.089 \\
\hline GCPII $1561 \mathrm{C} \rightarrow \mathrm{T}$ & $\mathrm{C} / \mathrm{C}$ & $\mathrm{C} / \mathrm{T}$ & $\mathrm{T} / \mathrm{T}$ & C & $\mathrm{T}$ & \\
\hline NTD case & $159(76.4)$ & $48(23.1)$ & $1(0.5)$ & 0.880 & 0.120 & 0.322 \\
\hline NTD case father & $67(72.8)$ & 25 (27.2) & $0(0.0)$ & 0.864 & 0.136 & 0.207 \\
\hline NTD case mother & $141(70.5)$ & $56(28.0)$ & $3(1.5)$ & 0.845 & 0.155 & 0.427 \\
\hline Control child & $458(76.3)$ & $137(22.8)$ & $5(0.8)$ & 0.878 & 0.123 & 0.181 \\
\hline Control mother & $382(71.9)$ & $143(26.9)$ & $6(1.1)$ & 0.854 & 0.146 & 0.080 \\
\hline CBS 844ins68 & W/W & $\mathrm{W} / \mathrm{I}$ & $1 / 1$ & W & 1 & \\
\hline NTD case & $174(84.0)$ & $31(15.0)$ & $2(1.0)$ & 0.915 & 0.085 & 0.642 \\
\hline NTD case father & $79(84.9)$ & $14(15.1)$ & $0(0.0)$ & 0.925 & 0.075 & 1.000 \\
\hline NTD case mother & $163(81.1)$ & 37 (18.4) & $1(0.5)$ & 0.903 & 0.097 & 0.701 \\
\hline Control child & $516(85.9)$ & 81 (13.5) & $4(0.7)$ & 0.926 & 0.074 & 0.557 \\
\hline Control mother & $456(84.1)$ & 81 (14.9) & $5(0.9)$ & 0.916 & 0.084 & 0.571 \\
\hline RFC-1 80G $\rightarrow \mathrm{A}$ & $G / G$ & $A / G$ & $\mathrm{~A} / \mathrm{A}$ & A & $\mathrm{G}$ & \\
\hline NTD case & $67(32.5)$ & $93(45.1)$ & $46(22.3)$ & 0.449 & 0.551 & 0.207 \\
\hline NTD case father & $26(28.3)$ & $46(50.0)$ & $20(21.7)$ & 0.533 & 0.467 & 1.000 \\
\hline NTD case mother & $58(29.0)$ & $96(48.0)$ & $46(23.0)$ & 0.530 & 0.470 & 0.672 \\
\hline Control child & $200(33.2)$ & $304(50.5)$ & 98 (16.3) & 0.415 & 0.585 & 0.356 \\
\hline Control mother & $172(31.9)$ & $262(48.6)$ & $105(19.5)$ & 0.438 & 0.562 & 0.793 \\
\hline SHMT $1420 \mathrm{C} \rightarrow \mathrm{T}$ & $\mathrm{C} / \mathrm{C}$ & $\mathrm{C} / \mathrm{T}$ & $\mathrm{T} / \mathrm{T}$ & C & $\mathrm{T}$ & \\
\hline NTD case & $99(49.5)$ & $82(41.0)$ & $19(9.5)$ & 0.700 & 0.300 & 0.737 \\
\hline NTD case father & 45 (49.5) & $33(36.3)$ & 13 (14.3) & 0.676 & 0.324 & 0.989 \\
\hline NTD case mother & $98(50.3)$ & $79(40.5)$ & $18(9.2)$ & 0.705 & 0.295 & 0.731 \\
\hline Control child & $284(47.4)$ & $250(41.7)$ & $65(10.9)$ & 0.683 & 0.317 & 0.396 \\
\hline Control mother & $231(44.8)$ & $220(42.6)$ & 65 (12.6) & 0.661 & 0.339 & 0.280 \\
\hline
\end{tabular}




\begin{tabular}{|c|c|c|c|c|c|c|}
\hline & \multicolumn{3}{|c|}{ NTD cases } & \multicolumn{3}{|c|}{ NTD case mothers } \\
\hline & OR & {$[95 \% \mathrm{Cl}]$} & $\mathrm{p}$ value & OR & {$[95 \% \mathrm{Cl}]$} & $p$ value \\
\hline $\begin{array}{l}\text { MTHFR } 677 \mathrm{C} \rightarrow \mathrm{T} \\
\mathrm{CC} \vee \mathrm{CT}+\pi \mathrm{T}\end{array}$ & 2.03 & {$[1.09,3.79]$} & 0.025 & 0.72 & {$[0.37,1.39]$} & \\
\hline MTHFR 1298A $\rightarrow$ C & & & & & & \\
\hline $\begin{array}{l}\mathrm{AA} \vee \mathrm{AC}+\mathrm{CC} \\
\text { MTRR } 66 \mathrm{~A} \rightarrow \mathrm{G}\end{array}$ & 1.63 & {$[0.89,3.00]$} & & 1.55 & {$[0.83,2.88]$} & \\
\hline $\begin{array}{l}\mathrm{AA} \vee \mathrm{AG}+\mathrm{GG} \\
\mathrm{GCPII} 1561 \mathrm{IC} \rightarrow \mathrm{T}\end{array}$ & 0.31 & {$[0.10,0.94]$} & 0.04 & 0.46 & {$[0.19,1.09]$} & \\
\hline $\begin{array}{l}\text { CC } v \text { CT+T } \\
\text { CBS 844ins } 68\end{array}$ & 1.05 & {$[0.53,2.09]$} & & 1.09 & {$[0.59,2.02]$} & \\
\hline WW $v$ Wl+II & 1.27 & {$[0.53,3.02]$} & & 1.22 & {$[0.56,2.69]$} & \\
\hline $\begin{array}{l}R F C-180 \mathrm{~B} \rightarrow \mathrm{A} \\
\mathrm{GG} \vee \mathrm{GA}+\mathrm{AA} \\
\text { SHMT 1420C } \rightarrow \mathrm{T}\end{array}$ & 1.29 & {$[0.65,2.55]$} & & 0.69 & {$[0.35,1.36]$} & \\
\hline $\mathrm{CC} \vee \mathrm{CT}+\mathrm{T}$ & 0.92 & {$[0.67,1.27]$} & & 0.64 & {$[0.36,1.14]$} & \\
\hline
\end{tabular}

subsequent studies in other populations have been unable to confirm this finding, ${ }^{25-28}$ a meta-analysis conducted by Botto and Yang ${ }^{10}$ identified an overall odds ratio of 1.75 [95\% CI $1.14,2.18$ ] in NTD cases. Previous studies have also shown MTHFR $677 \mathrm{C} \rightarrow$ T to represent a risk factor in mothers of NTD cases. ${ }^{10}$ However, in our NTD case mother population, the $677 \mathrm{C} \rightarrow \mathrm{T}$ variant was not shown to confer any risk. Indeed, no individual locus in mothers of NTD cases was shown to significantly influence risk of NTD pregnancy in our cohort.

Since both hyperhomocysteinemia and elevated vitamin $\mathrm{B}_{12}$ levels are independent indicators of NTD risk, ${ }^{29}$ some attention has focused on methionine synthase, an enzyme which catalyses the vitamin $\mathrm{B}_{12}$ dependent remethylation of Hcy to methionine, as a likely NTD risk factor. However, the MS $2756 \mathrm{~A} \rightarrow \mathrm{G}$ polymorphism has not been linked to NTD in British cases, ${ }^{25-28}$ although Doolin et $a l^{30}$ have recently suggested that this polymorphism may be a risk factor via the maternal line. Since methionine synthase reductase (MTRR) is involved in maintaining MS in an active state, it is also seen as a prime candidate. The results of this study suggest that the MTRR $66 \mathrm{~A} \rightarrow \mathrm{G}$ polymorphism acts to protect against NTD but only in cases $(p=0.04)$ and not case mothers $(p=0.08)$. This could be interpreted as the A allele representing the risk allele in our study population. In a previous study Wilson et al hypothesised that the $66 \mathrm{G}$ represented the mutant allele on the basis of an evolutionary conserved isoleucine codon (A allele). ${ }^{16}$ Subsequently, Gaughan et al ${ }^{29}$ have shown that it is the AA genotype that exhibits elevated Hcy. Typically, the A allele is at lower frequency in studies of MTRR, ${ }^{16}{ }^{29}$ as it is in this study. Wilson et $a l^{16}$ detected a significant increase in risk of NTD for carriers of the MTRR $66 \mathrm{G}$ allele when cobalamin levels were low, or when combined with the MTHFR $677 \mathrm{C} \rightarrow$ T mutant genotype, and more recently Zhu et al reported an association between the $G$ allele and NTD risk in a US population. ${ }^{31}$ However, Lucock et $a^{26}{ }^{27}$ were unable to implicate MTRR $66 \mathrm{~A} \rightarrow \mathrm{G}$ as a NTD risk factor in a UK population. We see a strongly reduced risk of NTD associated with the $66 \mathrm{G}$ allele of MTRR in our case population. These results must be interpreted with caution due to the observed deviation from HWE of MTRR genotypes in the NTD case group. The current study detected an interaction between MTHFR $677 \mathrm{C} \rightarrow \mathrm{T}$ and MTRR $66 \mathrm{~A} \rightarrow \mathrm{G}$ in NTD cases $(\mathrm{p}=0.003)$, which supports the observations of Wilson et al. ${ }^{16}$ A maternal (MTRR 66A $\rightarrow \mathrm{G}$ )-fetal $($ MTHFR $677 \mathrm{C} \rightarrow \mathrm{T})$ interaction which elevated NTD risk was also observed $(\mathrm{p}=0.001)$.

This study investigated the influence of gene-gene interaction on the risk of NTD in a sizeable population using multivariate logistic regression analysis to implicate a number of genes as risk factors for NTD. Previous studies have indicated that the possession of more than one polymorphism at folate-related loci can elevate risk of NTD. ${ }^{15}{ }^{16}$ The chosen method of analysis in this study did not involve a pair-wise analysis of genotype combinations but a logistic regression model to incorporate all seven loci.

Epistasis, or the interaction between genes, is a phenomenon of increasing importance in the field of genetic epidemiology. As a statistical concept, analysis of epistasis can lead to improved power for the detection of genetic effects. ${ }^{32}{ }^{33}$ There is however some discussion as to the differing use of the term epistasis in a statistical or biological context. It has been adopted here as a statistical term with the caveat that it can be difficult to infer biological meaning from quantitative data measuring disease risk as the outcome. ${ }^{334}$ With regard to polymorphisms in the folatedependent Hcy metabolic pathway, a substantial amount is known about the biological role of the candidate genes under investigation, therefore a plausible biological model could be postulated for the epistatic events observed. The benefit of the analysis of epistasis therefore does not lie in further elucidating biological mechanisms underlying disease pathogenesis, but in determining the true contribution of genetic factors to disease susceptibility.

As discussed above, when tested independently, the MTHFR $677 \mathrm{C} \rightarrow \mathrm{T}$ polymorphism represents a risk factor (OR 2.03 [95\% CI $1.09,3.79] \mathrm{p}=0.025)$ and the MTRR $66 \mathrm{~A} \rightarrow \mathrm{G}$ polymorphism, a protective effect (OR 0.31 [95\% CI 0.10 , 0.94]). Furthermore, when found in combination, these variants significantly influence NTD risk in NTD cases. In addition, the MTHFR $677 \mathrm{C} \rightarrow \mathrm{T}$ variant in combination with the $C \beta S$ 844ins68 variant inflates the individual effect of the MTHFR $677 \mathrm{C} \rightarrow$ T variant $(\mathrm{p}=0.007)$. Such epistatic effects are difficult to interpret but may go some way to explain the varying findings of different polymorphism studies. Clearly a broader haplotype must be considered in relation to NTDrelated polymorphisms to allow an accurate assessment of disease risk.

It is clear that maternal genotype can impact upon pregnancy outcome, ${ }^{30} 35$ with further influence possible from maternal-fetal interaction. ${ }^{37}$ Christensen et al reported a notable elevation in NTD risk, from a non-significant risk in individual cases or mothers, when the MTHFR $677 \mathrm{C} \rightarrow \mathrm{T}$ variant was harboured by both mother and offspring (odds ratio (OR) for TT/TT genotype combination: 6.00 [95\% CI $1.26,28.53]) .^{38}$ Although this finding is not replicated using the statistical model applied in the context of this study, one 
example of statistically significant maternal-fetal interaction was demonstrated.

In summary, MTHFR $677 \mathrm{C} \rightarrow \mathrm{T}$ has been shown to represent a risk factor in NTD cases in a UK population. Furthermore, when interactions between this and other polymorphisms have been investigated, significant interactions have been observed. Molecular genetic advances are resulting in single locus investigations being superseded by multi-locus analyses, however interpretation of data is consequently complex. A significant challenge remains in translating the observations of association studies, such as those presented in this paper, to a clinical setting where NTD families are counselled with regard to genotype derived susceptibility.

\section{ACKNOWLEDGEMENTS}

We thank all those families affected by neural tube defects who consented to participating in this study, and ASBAH for their support. We thank Professor Yvonne Edwards for her helpful assistance in the early stages of the study.

\section{Authors' affiliations}

C L Relton, M S Pearce, Paediatric and Lifecourse Epidemiology Research Group, School of Clinical Medical Sciences, Newcastle University, Sir James Spence Institute, Royal Victoria Infirmary, Newcastle upon Tyne, NE1 4LP, UK

C S Wilding, A J Laffling, E J Tawn, Genetics Department, Westlakes Research Institute, Westlakes Science and Technology Park, Moor Row, Cumbria, CA24 3JY, UK

P A Jonas, West Cumberland Hospital, Whitehaven, Cumbria, CA28 8JG, UK

C L Relton, P A Jonas, S A Lynch, J Burn, Institute of Human Genetics, International Centre for Life, Central Parkway, Newcastle-upon-Tyne, NEI 3BZ, UK

This research was funded by BNFL and the Birth Defects Foundation. Conflict of interest: none declared.

\section{REFERENCES}

1 Botto LD, Moore CA, Khoury MJ, Erickson JD. Neural-tube defects. N Engl J Med 1999:341:1509-19.

2 Lucock M. Folic acid: nutritional biochemistry, molecular biology, and role in disease processes. Mol Genet Metab 2000;71:121-38.

3 Smithells RW, Sheppard S, Schorah CJ. Vitamin deficiencies and neural tube defects. Arch Dis Child 1976:51:944-50.

4 van der Put NMJ, Steegers-Theunissen RPM, Frosst $P$, Triibels FJM Eskes TKAB, van den Heuvel LP, Mariman ECM, den Heyer M, Rozen R, Blom HJ. Mutated methylenetetrahydrofolate reductase as a risk factor for spina bifida. Lancet 1995;346:1070-1

5 Steegers-Theunissen RPM, Boers GHJ, Trijbels FJM. Maternal hyperhomocysteinemia: a risk factor for neural-tube defects? Metabolism 1994;43:1475-80.

6 Whitehead AS, Gallagher P, Mills JL, Kirke PN, Burke H, Molloy AM, Weir DG, Sheilds DC, Scott JM. A genetic defect in 5,10methylenetetrahydrofolate reductase in neural tube defects. QJM 1995:88:763-6.

7 Barber RC, Lammer EJ, Shaw GM, Greer KA, Finnell RH. The role of folate transport and metabolism in neural tube defect risk. Mol Genet Metab 1999;66:1-9.

8 van der Put NMJ, van Straaten HWM, Triibels FJM, Blom HJ. Folate, homocysteine and neural tube defects: an overview. Exp Biol Med 2001;226:243-70.

9 Ming JE, Muenke M. Multiple hits during early embryonic development: digenic diseases and holoprosencephaly. Am J Hum Genet 2002;71:1017-32.

10 Botto LD, Yang Q. 5, 10-Methylenetetrahydrofolate reductase gene variants and congenital anomalies: a HuGE review. Am J Epidemiol 2000;151:862-77.

11 Rady PL, Szucs S, Grady J, Hudnall SD, Kellner LH, Nitowsky H, Tyring SK, Matalon RK. Genetic polymorphisms of methylenetetrahydrofolate reductase (MTHFR) and methionine synthase reductase (MTRR) in ethnic populations in Texas: a report of a novel MTHFR polymorphic site, G1793A. Am J Med Genet 2001;107:162-8.

12 Rankin J, Glinianaia S, Brown R, Renwick M. The changing prevalence of neural tube defects: a population-based study in the North of England, 19841996. Paediatr Perinat Epidemiol 2000;14:104-10.

13 Chase DS, Tawn EJ, Parker L, Jonas P, Parker OC, Burn J. The North Cumbria Community Genetics Project. J Med Genet 1998;35:413-6.
14 Frosst P, Blom HJ, Milos R, Goyette P, Sheppard CA, Matthews RG, Boers GJ, den Heijer M, Kluijmans LA, ven den Heuvel LP, Rozen R. A candidate genetic risk factor for vascular disease: a common mutation in methylenetetrahydrofolate reductase. Nat Genet 1995;10:111-3.

15 van der Put NMJ, Gabreëls F, Stevens EMB, Smeitink JAM, Triibels FJM, Eskes TKAB, van den Heuvel LP, Blom HJ. A second common mutation in the methylenetetrahydrofolate reductase gene: an additional risk factor for neuraltube defects? Am J Hum Genet 1998:62:1044-51.

16 Wilson A, Platt R, Wu Q, Leclerc D, Christensen B, Yang H, Gravel RA, Rozen R. A common variant in methionine synthase reductase combined with low cobalamin (vitamin $B_{12}$ ) increases risk for spina bifida. Mol Genet Metab 1999;67:317-23.

17 Brown CA, McKinney KQ, Kaufman JS, Gravel RA, Rozen R. A common polymorphism in methionine synthase reductase increases risk of premature coronary artery disease. J Cardiovasc Risk 2000;7:197-200.

18 Devlin AM, Ling EH, Peerson JM, Fernando S, Clarke R, Smith AD, Halsted $\mathrm{CH}$. Glutamate carboxypeptidase II: a polymorphism associated with lower levels of serum folate and hyperhomocysteinemia. Hum Mol Genet 2000;9:2837-44.

19 Ramsbottom D, Scott JM, Molloy A, Weir DG, Kirke PN, Mills JL, Gallagher PM, Whitehead AS. Are common mutations of cystathionine $\beta$-synthase involved in the aetiology of neural tube defects? Clin Genet 1997;51:39-42.

20 Chango A, Emery-Fillon N, Potier de Courcy G, Lambert D, Pfister M, Rosenblatt DS, Nicolas J-P. A polymorphism $(80 G \rightarrow A$ ) in the reduced folate carrier gene and its associations with folate status and homocysteinemia. Mol Genet Metab 2000;70:310-5.

21 Heil SG, van der Put NMJ, Waas ET, den Heijer M, Triibels FJM, Blom HJ. Is mutated serine hydroxymethyltransferase (SHMT) involved in the etiology of neural tube defects? Mol Genet Metab $2001 ; 73: 164-72$.

22 Guo SW, Thompson EA. Performing the exact test of Hardy-Weinberg proportion for multiple alleles. Biometrics 1992;48:361-72.

23 Schaid DJ, Jacobsen SJ. Biased tests of association: comparisons of allele frequencies when departing from Hardy-Weinberg proportions. Am J Epidemiol 1999;149:706-11.

24 van den Oord EJ, Vermunt JK. Testing for linkage disequilibrium, materna effects, and imprinting with (in)complete case-parent triads, by use of the computer program LEM. Am J Hum Genet 2000;66:335-8

25 Morrison K, Papapetrou C, Hol FA, Mariman ECM, Lynch SA, Burn J, Edwards YH. Susceptibility to spina bifida: an association study of five candidate genes. Ann Hum Genet 1998:62:379-96.

26 Lucock M, Daskalakis I, Briggs D, Yates Z, Levene M. Altered folate metabolism and disposition in mothers affected by a spina bifida pregnancy: influence of $677 \mathrm{c} \rightarrow$ t methylenetetrahydrofolate reductase and $2756 \mathrm{a} \rightarrow \mathrm{g}$ methionine synthase genotypes. Mol Genet Metab 2000;70:27-44.

27 Lucock M, Daskalakis I, Hinkins M, Yates Z. An examination of polymorphic genes and folate metabolism in mothers affected by a spina bifida pregnancy. Mol Genet Metab $2001 ; 73: 322-32$

28 De Marco P, Calevo MG, Moroni A, Arata L, Merello E, Finnell RH, Zhu H, Andreussi L, Cama A, Capra V. Study of MTHFR and MS polymorphisms as risk factors for NTD in the Italian population. J Hum Genet 2002;47:319-24.

29 Gaughan DJ, Kluiitmans LAJ, Barbaux S, McMaster D, Young IS Yarnell JWG, Evans A, Whitehead AS. The methionine synthase reductase (MTRR) A66G polymorphism is a novel genetic determinant of plasma homocysteine concentrations. Atherosclerosis 2001;157:451-6.

30 Doolin M-T, Barbaux S, McDonnell M, Hoess K, Whitehead AS, Mitchell LE. Maternal genetic effects, exerted by genes involved in homocysteine remethylation, influence the risk of spina bifida. Am J Hum Genet 2002;71:1222-6.

31 Zhu H, Wicker NJ, Shaw GM, Lammer EJ, Hendricks K, Suarez L, Canfield M Finnell RH. Homocysteine remethylation enzyme polymorphisms and increased risk for neural tube defects. Mol Genet Metab 2003;78:216-21.

32 Clayton D, McKeigue PM. Epidemiological methods for studying genes and environmental factors in complex diseases. Lancet 2001;358:1356-60.

33 Cordell HJ. Epistasis: what it means, what it doesn't mean, and statistical methods to detect it in humans. Hum Mol Genet 2002;11:2463-8.

34 Thompson WD. Effect modification and the limits of biological inference from epidemiologic data. J Clin Epidemiol 1991;44:221-32.

35 Moyers S, Bailey LB. Fetal malformations and folate metabolism: review of recent evidence. Nutr Rev 2001;59:215-35.

36 Nelen WLDM, Blom HJ, Thomas CMG, Steegers EAP, Boers GHJ, Eskes TKAB. Methylenetetrahydrofolate reductase polymorphism affects the change in homocysteine and folate concentrations resulting from low dose folic acid supplementation in women with unexplained recurrent miscarriages. J Nutr 1998; 128:1336-41.

37 Shields DC, Kirke PN, Mills JL, Ramsbottom D, Molloy AM, Burke H, Weir DG Scott JM, Whitehead AS. The "thermolabile" variant of methylenetetrahydrofolate reductase and neural tube defects: an evaluation of genetic risk and the relative importance of the genotypes of the embryo and the mother. Am J Hum Genet 1999;64:1045-55.

38 Christensen B, Arbour L, Tran P, Leclerc D, Sabbaghian N, Platt R, Gilfix BM Rosenblatt DS, Gravel RA, Forbes P, Rozen R. Genetic polymorphisms in methylenetetrahydrofolate reductase and methionine synthase, folate levels in red blood cells and risk of neural tube defects. Am J Med Genet 1999:84:151-7. 